\title{
Optimization of Cross-Border e-Commerce Logistics Supervision System Based on Internet of Things Technology
}

\author{
Pingping Sun ${ }^{1}$ and Lingang Gu $\mathbb{D}^{2}$ \\ ${ }^{1}$ Business \& Tourism Institute, Hangzhou Vocational \& Technical College, Hangzhou, Zhejiang 310018, China \\ ${ }^{2}$ Special Equipment Institute, Hangzhou Vocational \& Technical College, Hangzhou, Zhejiang 310018, China \\ Correspondence should be addressed to Lingang Gu; 1999010004@hzvtc.edu.cn
}

Received 17 April 2021; Revised 12 May 2021; Accepted 20 May 2021; Published 27 May 2021

Academic Editor: Zhihan Lv

Copyright (c) 2021 Pingping Sun and Lingang Gu. This is an open access article distributed under the Creative Commons Attribution License, which permits unrestricted use, distribution, and reproduction in any medium, provided the original work is properly cited.

\begin{abstract}
Based on the Internet of Things technology, this paper proposes building a cross-border e-commerce logistics supervision system and determines the evaluation index system from the overall framework design of the system, supply chain supervision process optimization, risk supervision optimization, and system order degree optimization. First of all, the framework adopts the national certification center to supervise the logistics service platform and logistics service platform to supervise the logistics participants of the secondary supervision system. Then, functions such as swarm intelligence contract, legal anonymous identity authentication, intelligent transaction matching, abnormal data analysis and detection, privacy protection, and traceability are realized under the framework of the supervision system. Then, the security analysis and transaction supervision component software are used to verify the security, control, and operating efficiency of the transaction supervision framework. Finally, in a real crowd sourcing logistics enterprise platform to run on the software component, the actual measurement, the measured results show that the proposed cross-border supervision system is safe and controllable, and electronic business logistics protects users and data privacy, prevents forgery and fraud, and realizes the user behavior and user data in addition to auditability and traceability.
\end{abstract}

\section{Introduction}

In recent years, the application of cross-border e-commerce is more and more widespread, and cross-border electronic logistics is also closely followed. One of the most important advantages of cross-border e-commerce is that it is able to break through the national boundaries of the traditional commerce; e-commerce may conduct business transactions between different countries, change the traditional offline trading patterns into online, and make the process more convenient and quick, combining the way of traditional logistics and e-commerce [1]. Cross-border e-commerce makes the circulation of goods at home and abroad much smoother, breaking the traditional commodity trading time and regional restrictions, but there are still some problems in the process of commodity transportation, because the national customs are very strict on the inspection of crossborder goods. Therefore, the cross-border electronic logistics will face very strict customs screening and will also face different problems raised by the customs agencies of various countries. But in recent years, the cross-border e-commerce industry in China has been making continuous progress, which has also led to the development of the national economy to a large extent. Therefore, the country has launched a variety of supporting policies, which undoubtedly makes the development of cross-border e-commerce quite faster.

The development of cross-border e-commerce needs the support of fast and safe logistics delivery and requires a higher level of logistics service to improve competitiveness. The main logistics problems faced by small- and mediumsized enterprises in the development of cross-border e-commerce in Quanzhou mainly include the following aspects: the high logistics cost, weakening the price advantage of cross-border e-commerce products; the long logistics links affecting the timeliness of cross-border e-commerce; the complex logistics process increasing the risk of cross-border e-commerce; the low level of logistics 
informatization affecting the customer experience of crossborder e-commerce; the shortage of cross-border logistics talents affecting the rapid development of cross-border e-commerce [2]. Therefore, this paper aims to analyze the development status of cross-border e-commerce and the application of Internet of Things technology, find out the logistics problems faced by enterprises in the development of cross-border e-commerce, and try to find out the countermeasures to solve these problems. It is hoped that this study can provide theoretical reference for relevant research and provide reference for the rationalization of cross-border e-commerce logistics.

The rest of this article is organized as follows: Section 2 discusses the relevant work. Section 3 elaborates the crossborder e-commerce logistics supervision system based on Internet of Things technology. Section 4 presents functional optimization and testing of cross-border e-commerce logistics supervision system. Section 5 summarizes the text. Under the framework of the monitoring system, this paper realizes the functions of group intelligent contract, legal anonymous identity authentication, intelligent transaction matching, abnormal data analysis and detection, privacy protection, and traceability. Then the security, controllability, and operating efficiency of the framework are verified by security analysis and transaction monitoring software. The measurement results show that the proposed crossborder logistics supervision system is secure and controllable and can protect the privacy of e-commerce logistics users and data, prevent forgery and fraud, and achieve the auditability and traceability of user behavior and user data.

\section{Related Work}

The development of cross-border e-commerce cannot be separated from the support of cross-border logistics. Only when the two develop together can they achieve a win-win situation. According to the collation and analysis of the published literature, it is found that experts and scholars mainly conduct research from two aspects in the research process: Ma et al. [3] analyzed the commonly used logistics modes and characteristics of cross-border e-commerce in China. Li et al. [4] analyzed the diversified demands of crossborder e-commerce and its development status in China and proposed a logistics and transportation mode suitable for cross-border e-commerce. Xie et al. [5] chose India as the research object, discussed the mode adopted in the development of cross-border e-commerce, analyzed the problems and countermeasures in the development of cross-border e-commerce, and laid a foundation for the development of cross-border e-commerce logistics mode in other countries. Taking China as the research object, Zhang et al. [6] discussed in detail the e-commerce development mode that can be adopted by small foreign trade agency enterprises in the development process and analyzed the development status and existing problems of their cross-border e-commerce. At the same time, the countermeasures that can be taken in the process of its development are given. It is concluded that foreign experts and scholars pay great attention to the analysis of the development model of e-commerce in the research process and analyze the existing problems and countermeasures in the use of the existing model. These analyses provide reference for the development of cross-border e-commerce model of freight forwarders in China. Secondly, as for the research on the development strategy of crossborder e-commerce logistics, Sun et al. [7] analyzed the crossborder logistics mode that can be adopted in China's tea and clothing industries. Porambage et al. [8] proposed that crossborder e-commerce enterprises should form a good cooperative relationship with cross-border logistics enterprises, so as to ensure the logistics and transportation quality of crossborder e-commerce commodities under the $\mathrm{B} 2 \mathrm{C}$ mode, reduce logistics and transportation costs, and improve logistics and transportation efficiency. Mohammed et al. [9] analyzed the commodity transport channels adopted by cross-border logistics enterprises and used empirical methods to verify the application of e-commerce platforms in the development process of cross-border e-commerce. Cao et al. [10] analyzed win-win cooperation approaches between cross-border e-commerce enterprises and logistics enterprises and pointed out that the Internet is the key to maintain their relationship. It can be concluded that when foreign experts study crossborder e-commerce logistics, they make targeted analysis on its existing problems and put forward specific solutions. These solutions can provide reference for the sustainability of crossborder e-commerce business development of Chinese freight forwarding enterprises.

There are also a large number of researches on crossborder e-commerce logistics supervision based on the Internet of Things technology in the literature. Through sorting and analysis, the research are mainly carried out from the following three aspects: Firstly, on the research of cross-border e-commerce and international logistics supervision mode, Xiao et al. [11] take the third-party logistics as the research object, analyze the development mode adopted in the context of cross-border e-commerce and the problems existing in the existing mode, and then put forward the countermeasures that can be taken. Mou et al. [12] chose Company $\mathrm{T}$ as the research object to analyze the logistics regulatory operation mode under the background of cross-border e-commerce and discussed from the aspects of its monitoring system, logistics service, operation technology, and transportation economy. Ai et al. [13] chose foreign trade enterprises as the research object to analyze their logistics and transportation supervision mode under the background of cross-border e-commerce. Secondly, regarding the research on the current situation of crossborder e-commerce logistics and the problems faced in supervision, Zhang et al. [14] take cross-border logistics enterprises as the research object, analyze the business models they can adopt and the regulatory problems they face in the process of economic globalization development, and then put forward corresponding solutions, so as to provide better logistics and transportation services for the development of cross-border e-commerce. Li [15] selected China's Heilongjiang province as the research object to analyze the problems in its cross-border commodity transportation process and the supervision scheme, that is, to further optimize the cross-border commodity logistics 
and transportation process through the introduction of information technology and personnel training. Thirdly, on the research of cross-border e-commerce logistics supervision strategies, $\mathrm{Li}$ et al. [16] proposed the necessity and advantages of the development of third-party logistics through the analysis of the current development of crossborder e-commerce in China and proposed specific supervision strategies. Sun et al. [17] also chose the third-party logistics as an example to discuss the relevant situation of its development under the background of cross-border e-commerce and analyzed its development problems from internal and external aspects. Finally, combined with the specific situation of the development of the third-party logistics of cross-border e-commerce in China, the optimization strategies that can be adopted are proposed.

\section{Cloud Audit Platform for Social Security Funds}

3.1. Construction of Basic Platform. To achieve effective electronic logistics supervision, it is necessary to consider the construction of a reasonable cross-border e-commerce and logistics collaborative platform. There is a mutual promotion and inseparable relationship between cross-border e-commerce and logistics. The development of cross-border e-commerce cannot be separated from the support and guarantee of logistics, and the development of logistics also needs the strong promotion of cross-border e-commerce. Although cross-border e-commerce and logistics belong to two different industries, they are actually a whole and closely linked to each other. The coordinated development of the two has an important impact and significance on the economic growth and development of a region and even a country. According to the composite system theory, crossborder e-commerce and logistics belong to two systems, but they are contained in a large composite system, and belong to two subsystems. The two subsystems are affected by a variety of factors, which can affect the structure, behavior, and function of the system and can be called order parameters. The size of these factors reflects the operating state and order degree of the subsystem in different stages. Based on the construction and research of the synergistic degree model, this paper constructs the synergistic development model of cross-border e-commerce and logistics.

3.1.1. Construction of Subsystem Order Degree Model. Suppose that the composite system of cross-border e-commerce and logistics is $S_{i}$, where $i=1,2$, that is, $S_{i}=\left\{S_{1}\right.$, $\left.S_{2}\right\}, S_{1}$ and $S_{2}$, respectively, represent the subsystem of crossborder e-commerce and logistics in the composite system. The order parameters in the subsystem development process can be used $e_{i}=\left(e_{i 1}, e_{i 2}, \ldots, e_{\mathrm{ij}}\right)$, where $j=1,2,3, \ldots, n$, $\alpha_{i j} \leq e_{i j} \leq \beta_{i j}, \alpha_{i j}$ and $\beta_{i j}$ are, respectively, the upper and lower limits of the order parameter index data of the critical point of system stability [18]. Then the value range of the order parameter of the cross-border e-commerce subsystem is $\alpha_{1 j} \leq e_{1 j} \leq \beta_{1 j}$, and the value range of the order parameter of the logistics subsystem is $\alpha_{2 j} \leq e_{2 j} \leq \beta_{2 j}$.
The order parameter is the degree of system ordering and the measure of the collaborative development of subsystems. Its size represents the degree of macroorder. When the order parameter is zero, the system is disordered [19]. When $E_{\mathrm{i} 1}, E_{\mathrm{i} 2}$, $\ldots, E_{i j}$ represents the benefit index, the larger the value is, the higher the degree of order is; the smaller the value is, the lower the degree of order is. When $E_{i 1}, E_{i 2}, \ldots, E_{i j}$ represents the cost index, the larger the value is, the lower the degree of order is; and the smaller the value is, the higher the degree of order is. Therefore, the order degree of order parameter component index $e_{i j}$ of the subsystem can be defined by its efficiency function, that is, the contribution degree of each order parameter index in the subsystem, as shown in

$$
\mu\left(e_{i j}\right)= \begin{cases}\frac{e_{i j}-\alpha_{i j}}{\alpha_{i j}+\beta_{i j}}, & i=1,2, \ldots, n ; j=1,2, \ldots, n, \\ \frac{e_{i j}-\beta_{i j}}{\alpha_{i j}+\beta_{i j}}, & i=1,2, \ldots, n ; j=1,2, \ldots, n .\end{cases}
$$

Starting from the whole composite system, the overall coordination and development of the system is not only determined by the contribution of order parameter components in the subsystem, but also determined by the integration and integration among order parameters. Therefore, the calculation of subsystem order degree can be realized by the integration of the function $\mu\left(e_{i j}\right)$ of order parameter $e_{i}$ [20]. Therefore, the order degree of the statutory subsystem can be calculated by linear weighting, as shown in

$$
u_{i}\left(e_{j}\right)=\sum_{i=1}^{n} u_{i}\left(e_{i j}\right) \cdot w_{i}^{2},
$$

where $u_{i}\left(e_{i}\right)$ in the formula represents the subsystem order degree, and $0 \leq u_{i}\left(e_{i}\right) \leq 1$. The larger the value is, the greater the contribution will be and the higher the subsystem order degree will be. $w_{j}$ is the weight coefficient of each order parameter component index, namely, the relative weight of each order parameter, and refers to the role of each order parameter in the ordered development process of the subsystem.

\subsubsection{Establishment of the System Synergy Degree Model.} The development of cross-border e-commerce and logistics is a process of dynamic evolution, and the relationship and function between various subsystems are not invariable [21-23]. Therefore, the degree of order and synergistic effect in different periods should be dynamically measured with the development $[24,25]$. Assume that the order degree of subsystem $\mathrm{Si}$ of the composite system of cross-border e-commerce and logistics is $u_{i}^{t 0}\left(e_{i}\right)$ at the initial stage of $t_{0}$ and $u_{i}^{t 1}\left(e_{i}\right)$ at the moment of $T 1$ in the development and evolution process and then in the process of development from $t_{0}$ to $t_{1}$. The synergistic degree of the composite system composed of two subsystems, cross-border e-commerce and logistics, is $U$, and the calculation of $U$ is shown in the following formula: 


$$
U=\lambda\left(\prod \frac{\left|u_{i}^{t_{1}}\left(e_{i}\right)-u_{i}^{t_{0}}\left(e_{i}\right)\right|}{u_{i}^{t_{0}}\left(e_{i}\right)}\right)^{1 / n}, \quad \text { where } \lambda= \begin{cases}0, & u_{i}^{t_{1}}\left(e_{i}\right) \geq u_{i}^{t_{0}}\left(e_{i}\right) \\ 1, & u_{i}^{t_{1}}\left(e_{i}\right)<u_{i}^{t_{0}}\left(e_{i}\right) .\end{cases}
$$

It can be seen from the formula that the degree of synergy between cross-border e-commerce and logistics system is obtained by the change of the order degree of subsystems, and the value range of its degree of synergy $U$ is $[-1,1]$. The closer it is to 1 , the higher the degree of synergy between cross-border e-commerce and logistics will be, and the closer it is to -1 , the lower the degree of synergy of the system will be. The synergy model constructed above fully analyzes the orderly development of the two subsystems and provides a systematic basis for the establishment of an effective and feasible supervision system.

\subsection{Structure of Cross-Border E-Commerce Logistics Network.} Based on the characteristics of cross-border e-commerce, the structure of cross-border logistics network is divided into three stages: logistics of the exporting country, international logistics, and logistics of the importing country. The nodes are the sellers of cross-border e-commerce, the transit warehouse of the exporting country, the transit point of international logistics, the bonded warehouse of the importing country, and consumers, respectively [8, 26, 27]. The connection between the nodes is the line connection between the nodes.

The five types of nodes in the cross-border e-commerce logistics network are (1) cross-border e-commerce sellers, including traditional enterprises, e-commerce enterprises, and individual merchants; (2) transit warehouse of the exporting country, where the exported commodities are gathered through the domestic logistics link to complete the process of commodity inspection and customs declaration; (3) international logistics transit points, including ports and airports, corresponding to water and air transport modes, respectively; (4) the bonded warehouse of the importing country, where the customs declaration and commodity inspection are completed, and some merchants keep their goods in the bonded warehouse of the customs, which is equivalent to the distribution center; (5) consumers. After the last kilometer of distribution, the goods finally reach the consumers, and the whole cross-border e-commerce logistics process is completed. The physical network topological structure formed by these nodes and the connections between nodes and the goods flow on the connections between nodes constitute the cross-border e-commerce logistics network system.

Cross-border e-commerce logistics network is composed of nodes and edges with different natures. To build a crossborder e-commerce logistics network model, these nodes and edges need to be abstracts into homogeneous nodes and edges of the network. The logistics network model of crossborder e-commerce is described as

$$
G=f(V, E, W, D, R) .
$$

In the formula, $G$ is the entire cross-border e-commerce logistics network; $V$ is the node set of cross-border e-commerce logistics network, including cross-border e-commerce sellers, transit warehouse of exporting country, transit point of international logistics, bonded warehouse of importing country, consumers, and other practical nodes. If $V=n$, it means that there are $n$ nodes in the network, $V=$ $\left\{v_{1}, v_{2}, v_{3}, \ldots, v_{n}\right\} . E$ is the side of cross-border e-commerce logistics network, including urban roads, sea routes, air $D=\left\{d_{i j} \mid i, j \in n\right\}$, is the set of load flow, and is also the set of edge weight. In this way, the cross-border e-commerce logistics network is transformed into a weighted undirected connected graph including cross-border e-commerce sellers, transit warehouses of exporting countries, international logistics transit points, bonded warehouses of importing countries, consumers, and logistics roads, as shown in Figure 1.

Cross-border e-commerce logistics network is distributed in the global scope, which has the characteristics of small batch, multifrequency, long distance, and being easy to be affected by spatial geographical conditions. At the same time, cross-border logistics passes through many intermediate nodes and has a long logistics cycle. In the cross-border e-commerce logistics network, nodes mainly realize different functions such as warehousing, packaging, and customs declaration. From the perspective of network structure, the degree of different nodes is very different, which has the characteristics of nonuniform distribution.

In the process of cross-border e-commerce logistics, there are five types of nodes, including cross-border e-commerce seller, transit warehouse of exporting country, transit point of international logistics, bonded warehouse of importing country, and consumer. When constructing network model with complex network theory, the nodes are abstracted into homogeneous network nodes without considering the heterogeneity of nodes. Therefore, this section takes the differences of nodes into consideration and divides the nodes of cross-border e-commerce logistics network into the following three categories: Class I nodes: terminal nodes, including nodes of cross-border e-commerce sellers and consumers. In comparison, the business volume of such nodes is small and the degree of such nodes is small.

The second is Class II node: midtransition logistics node, including transit node in the international transportation process such as transit port, airport, and railway station, as well as transit warehouse node in the exporting country, which realizes logistics transit activities such as functional storage, cargo collection, and distribution. This class of nodes is of medium degree.

The third is Class III node: middle transition function node. This kind of node refers to the customs and realizes the national inspection and commodity inspection of goods. When the goods need to be stored in the bonded warehouse, this kind of node also realizes the storage function. This class of nodes has the greatest degree. Connected nodes, the main routes, and highways. $D$ is the set of section distance, 


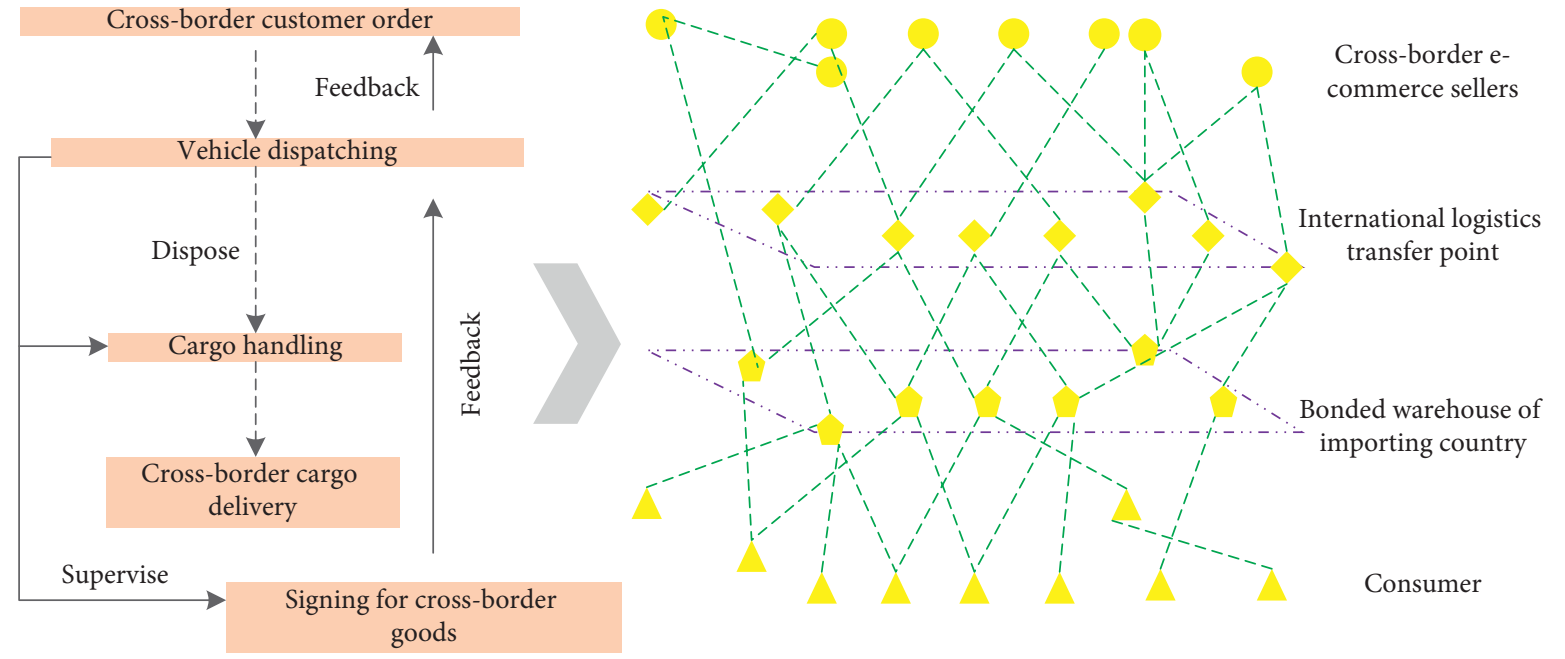

FIgURE 1: Cross-border e-commerce logistics network node schematic model.

function of transport cross-border electricity logistics network nodes between single transport cargo is small, but the current frequency of relatively more, and the frequency of different logistics process between different nodes, this leads to cross-border electricity logistics network, the edge load capacity is also different, this will be represented by the edge of the weight. At the same time, the weight of the node will also be expressed by the weight of the edge.

The cross-border e-commerce logistics network is similar to the general logistics network in that the flow of goods is $b_{i}$-directional, so the directional problem is not considered in the cross-border e-commerce network. To sum up, the cross-border e-commerce logistics network constructed in this paper is the undirected weighted network graph $G=\{V, W, R\}$, as shown in Figure 2, which represents the nodes in the network, represents the risk grade coefficient on the edge, and represents the weight of the edge in the network. Adjacency matrix is established according to network graph $G$, as detailed below:

$$
\begin{aligned}
& a_{i j}=\left\{\begin{array}{ll}
w_{i j} v_{i j}, & v_{i} \leq v_{j}, \\
0, & v_{i}>v_{j},
\end{array} \quad i=1,2, \ldots, n ; j=1,2, \ldots, n,\right. \\
& b_{i j}=\left\{\begin{array}{ll}
r_{i j} v_{i j}, & v_{i} \leq v_{j}, \\
0, & v_{i}>v_{j},
\end{array} \quad i=1,2, \ldots, n ; j=1,2, \ldots, n,\right.
\end{aligned}
$$

where $a_{i j}$ and $b_{i j}$, respectively, represent the values of the adjacency matrix in the horizontal and vertical directions, where $i=1,2,3, \ldots, n ; j=1,2,3, \ldots, n$.

\subsection{Construction of Cross-Border E-Commerce Logistics Su-} pervision System. This paper focuses on the theoretical framework of cross-border logistics monitoring and supervision and gives the corresponding implementation methods. The hierarchical and multilayer intelligent logistics regulatory framework is shown in Figure 3.
Each node on the chain usually has a corresponding industry, such as logistics and financial entities. Participants join the network through authorization and form a stakeholder alliance, which maintains the operation of the block chain. Therefore, as a general solution, this framework is applicable not only to the field of crowd sourced logistics, but also to other industrial areas such as inclusive finance. The whole transaction regulatory framework deploys two levels of regulatory points. Among them, the supervisory point $I$ is the top-level national authorized certification center of the supervisory structure, which is the trust root of the intelligent service transaction regulatory framework to deploy and implement the supervision module of enterprise implantation to the alliance chain of the registration marrow. All industries or organizations to the national authorized certification center to apply for the deployment of the implementation of the alliance chain need to provide the access proof including enterprise legal person, qualification certificate, and other entity information and sign the monitoring implant informed agreement section. Monitoring and implantation of informed agreement are a legal effect of the alliance chain implementer to accept the supervision of the superior competent department of the National Authorized Certification Center. It shows that all the transaction data and operation logs are authorized by the National Authorized Certification Center real-time access.

3.4. Logistics Supervision Methods Used by the System. This section takes the modern logistics service industry as an example to introduce the transaction supervision method supported by the hierarchical and multilayer intelligent logistics service regulatory framework. As shown in Figure 4, where 19 tags have been added, the implementation of the whole approach involves two aspects:

(1) Supervision of logistics service platforms by the National Certification and Authorization Center: the intelligent service platform first needs to submit the qualification to the national authorized certification 

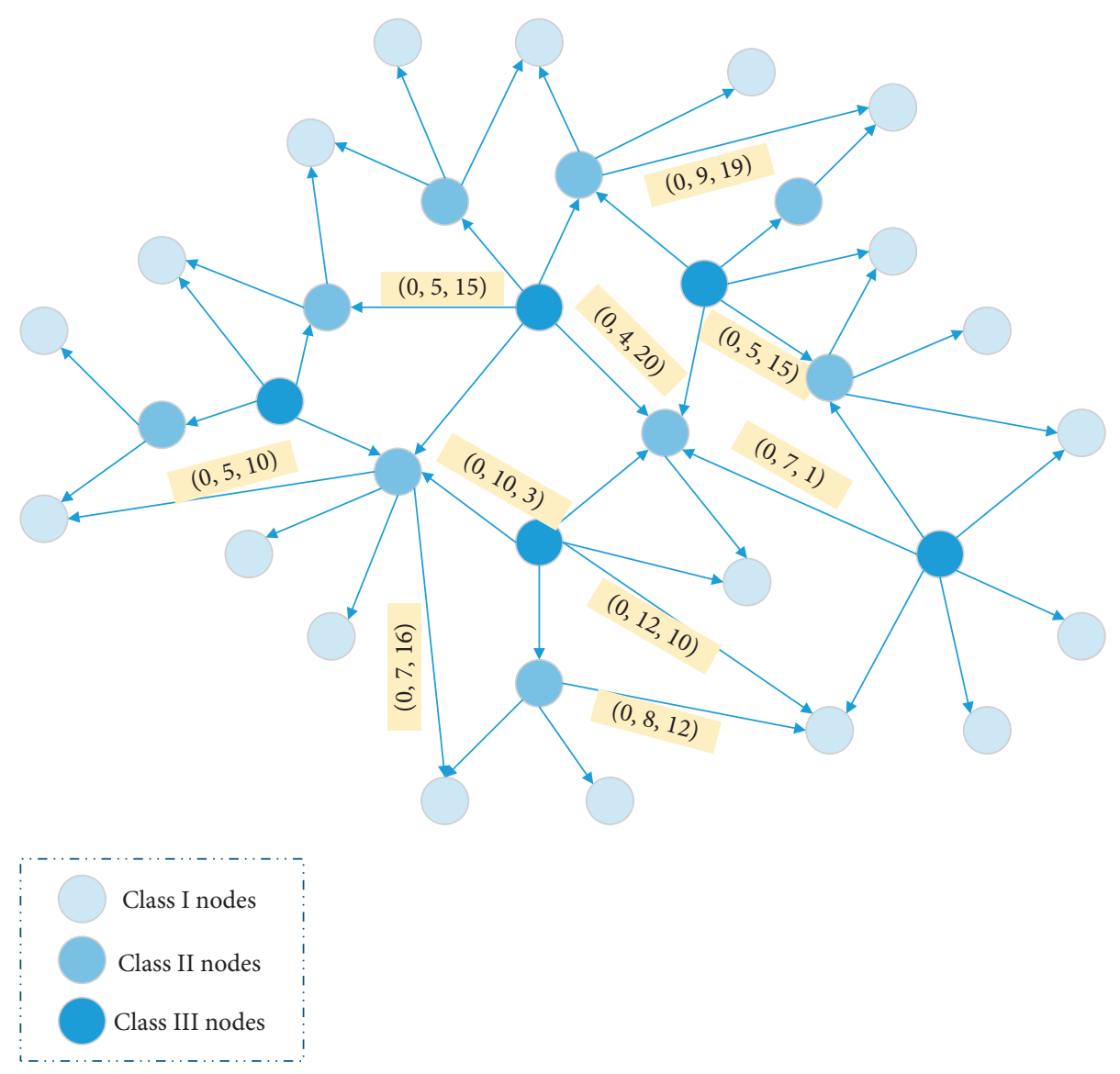

FIgURE 2: Schematic diagram of cross-border e-commerce logistics network nodes.
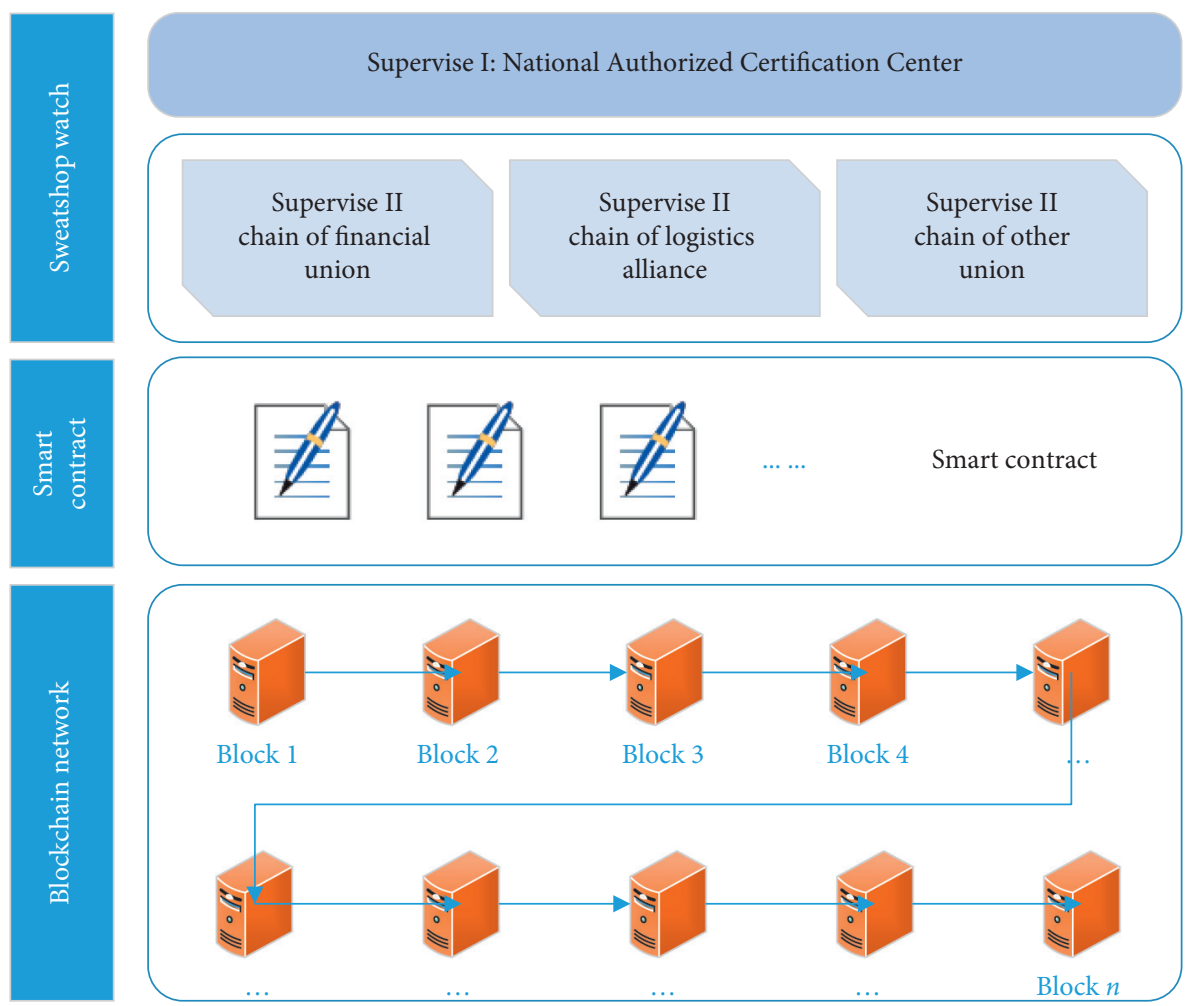

FIGURE 3: Hierarchical and multitiered intelligent logistics regulatory framework. 
center (AC). The National Authorized Certification Center shall conduct a comprehensive assessment on whether the logistics service platform has the qualifications after necessary identity, qualification, and reputation retrieval. If it has the service access qualification, it will be issued with the corresponding authorization license (license) to make it become a legal intelligent transaction service node. Strapped home authorization certification center to the logistics service platform issued the authorization license and the service platform industry alliance chain implants the corresponding functional level of regulatory functions. The logistics service process refers to the use of chain plug-ins embedded in the logistics service platform and industry alliance supervision functions by the national authorized certification center for data collection and online analysis. It captures the abnormal behavior in the process of the trade service platform in real time, such as the data on the behavior of prohibited items on the national chain.

(2) The logistics service platform has great influence on the main participants of logistics: logistic service requesters (Requester) and workers (Workers) register in the logistics service platform, and the service platform checks their identity, reputation, etc. (if necessary, they need to seek help from the National Reputation Center through the National Authorization Center). Requester (specifically and successfully registered) submits a logistics task request to the logistics service platform, and the server triggers a smart contract (running a specific task matching algorithm) to automatically match the logistics request with the Worker and submits the matching result to Miner. The service platform will reward and punish workers according to the completion of logistics tasks.

\section{Functional Optimization of Cross-Border E-Commerce Logistics Supervision System}

4.1. Implementation of the Regulatory Framework. The software architecture of the cross-border e-commerce logistics supervision system is shown in Figure 5.

The middle part is the intelligent logistics service center. It is divided into the overall architecture design, hierarchical multilayer supervision design, and monitoring node function design. The overall software architecture design includes the following functions and research contents: (1) regulation area division and node deployment, aiming at improving the efficiency, accuracy, and expansibility of regulation; (2) design of regulatory interface for intelligent service trading, that is, different regulatory access modes adopted for different types of energy service trading systems.

The functions of supervision node mainly include object identity authentication, transaction record storage, abnormal behavior gun detection, supervision action implementation, supervision log recording, and other functions.
Based on the above functional requirements, the intelligent service trading regulatory framework platform development includes verification of the built intelligent service trading regulatory platform availability and efficiency. At the same time, it verifies the availability and efficiency of the service transaction operation and supervision scheme focused on the supervision platform and the traceability scheme oriented to the multimodal transaction object, and then it comprehensively verifies the stability, real time, and accuracy of the intelligent service transaction supervision platform.

4.2. Risk Resistance Testing and Optimization. Now, it is assumed that there are 2 international logistics transit points, 8 cross-border e-commerce seller and exporter transit warehouses, and 10 cross-border e-commerce bonded warehouses and demand points. This network is abstracted into an undirected network weighting diagram with 20 nodes and 34 edges by using the representation method of complex network (as shown in Figure 6).

The simulation experiment process is as follows: in the random destruction simulation experiment, one node or edge is deleted randomly each time until all edges or nodes are deleted, and the results of 8 experiments are averaged. In the simulation experiment of intentional attack, the importance of nodes or edges is sorted according to the number of nodes or edges, and one node or edge is deleted each time from high to low. When there are multiple nodes or edges with the same number of nodes or edges, it is determined by random selection until all nodes or edges are deleted.

As can be seen from Figure 6, in the case of random destruction, the proportion of nodes deleted in the network reaches about $80 \%$, and the network risk efficiency drops to 0 , indicating that the network is in a state of paralysis at this time. However, in the case of deliberate attack, the proportion of nodes deleted in the network is about $60 \%$, and the network is in a state of paralysis. It can also be seen that intentional attacks are more destructive than random ones. All these indicate that the cross-border e-commerce logistics network is vulnerable to deliberate attacks and robust to random destruction, which proves that the cross-border e-commerce logistics network is a scale-free network. The loss caused by random sabotage and deliberate attack to cross-border e-commerce logistics network is almost the same. With the increase of the proportion of edge deletion, the loss caused by deliberate attack to network increases sharply. When the proportion of edge deletion reaches about $80 \%$, the loss caused by deliberate attack and deliberate attack tends to be the same. Again, intentional attacks are more destructive than random ones. Moreover, the stability of the network is maintained by the important edges. In the actual security maintenance of cross-border e-commerce logistics network, special attention should be paid to the protection of important traffic lines. Keeping the lines unblocked can effectively maintain the network structure, thus reducing the occurrence of network losses. 


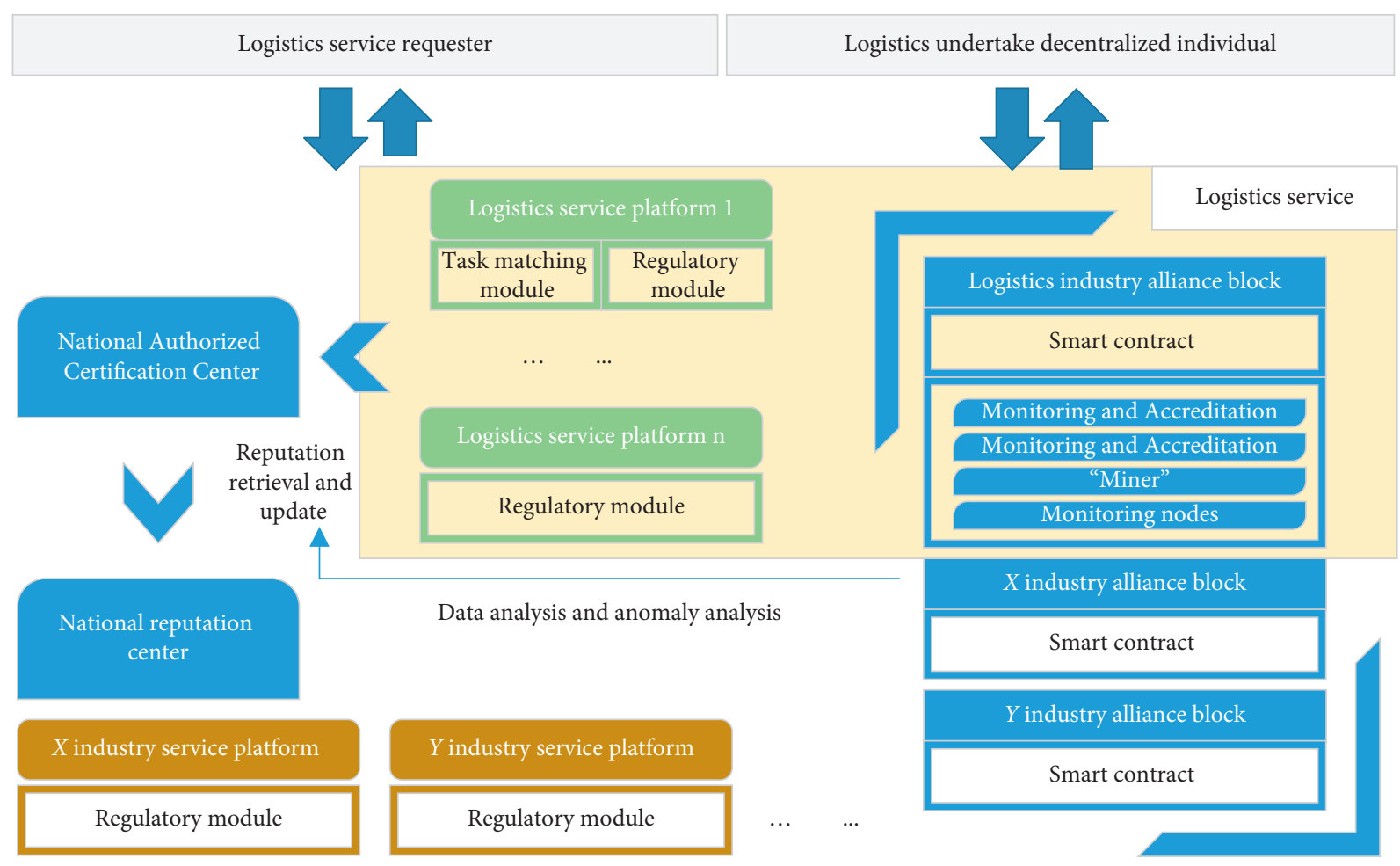

Figure 4: Electronic commerce logistics supervision methods.

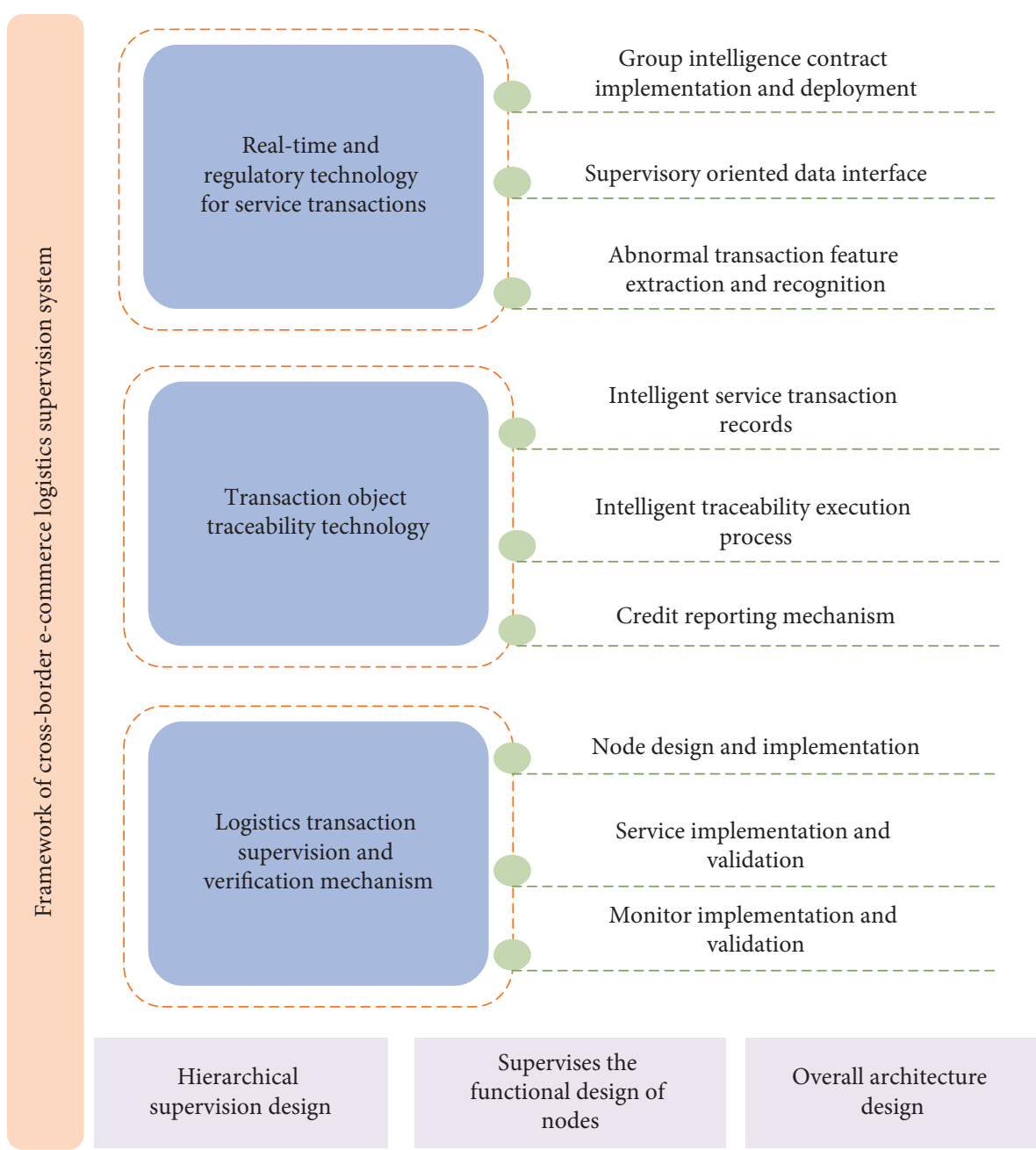

FIGURE 5: Software framework of cross-border e-commerce logistics supervision system. 


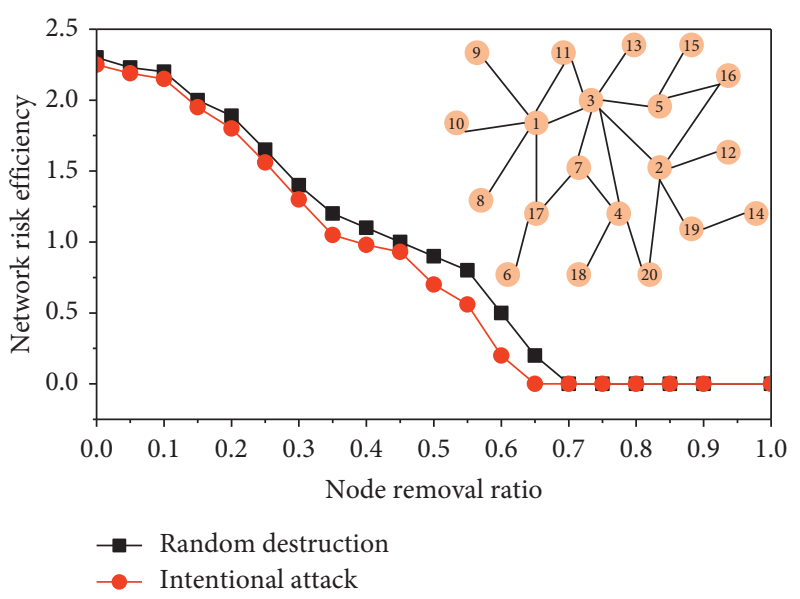

FIGURE 6: Changes of risk efficiency of cross-border e-commerce logistics network under different node attack strategies.

4.3. Optimization of Supply Chain Supervision. In terms of supply chain management, compared with traditional trade, the supply chain of cross-border e-commerce has the characteristics of fewer links in the whole supply chain process and convenient transaction mode. There are big differences in the way they are regulated. The import and export of cross-border e-commerce mainly include four regulatory modes: "bonded import online," "direct purchase import," "general export," and "export from special regions." As shown in Figure 7, crossborder e-commerce companies generally sell goods directly to consumers through manufacturers or brand owners, and there are only international logistics, overseas warehouse, bonded warehouse, and customs clearance procedures in the middle. In addition to the above process nodes, traditional trade generally involves general distributors, provincial distributors, regional distributors, and retailers. There are many transaction links and the overall cost of supply chain is high. Domestic consumers in cross-border electric business platform after order, the merchants of platforms, or the electric business platform will be the order of the order information, payment information, and logistics waybill information submitted to the customs special cross-border electricity cross-border import customs clearance formalities declaration system (i.e., cross-border business model declaration), and then the customs are in accordance with the terms of this commodity category such as tax rate and tax department. Import and retail tax shall be levied on the goods in the order, and automatic verification and cancellation shall be carried out on the commodity account book of the customs after the relevant information is verified and released.

The general trade mainly includes import and export declaration, inspection, payment of taxes and fees, goods release four supervisory links. For general trade import and export declaration, the first is the enterprise or individual, in accordance with the relevant law within the prescribed time limits, in the import and export port or close condition, the corresponding electronic customs clearance or paper declaration, declare to the customs import and export commodities actual situation, including the information such as quantity, price, countries, and regions, and then the customs to declare documents for review process. Then, it is

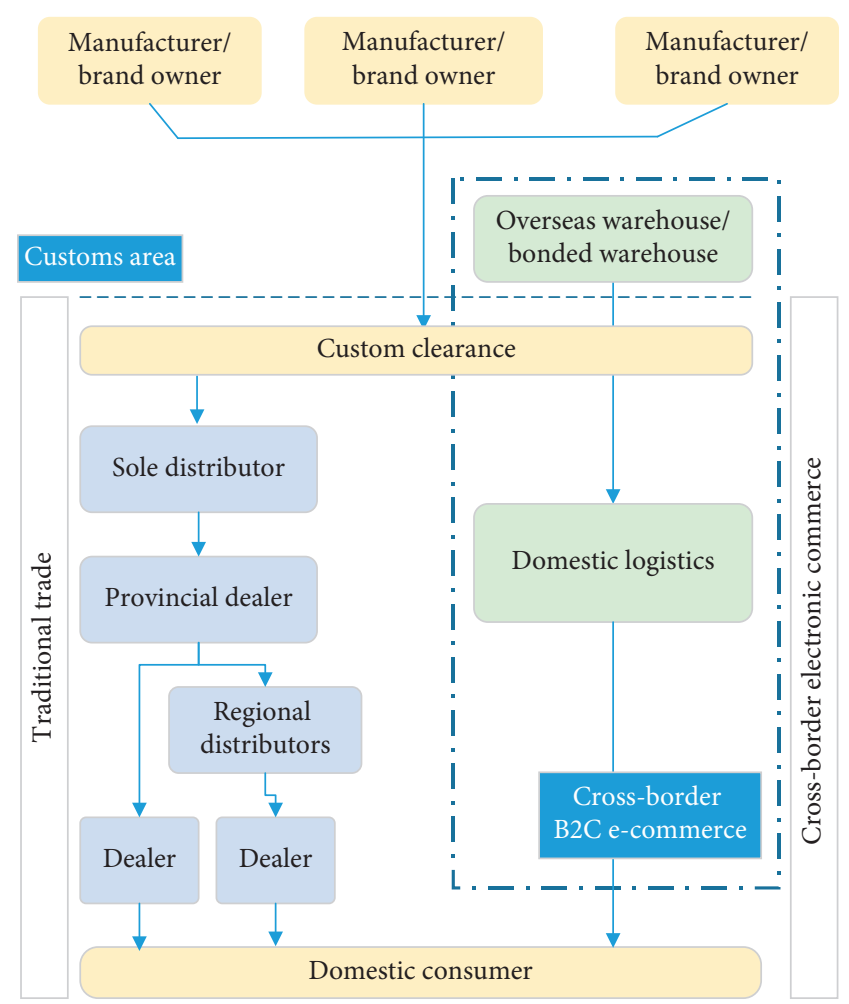

FIgURE 7: Supply chain difference between cross-border e-commerce and traditional trade.

necessary to cooperate with the customs for inspection. In order to determine whether the corresponding import and export commodities match with the declaration documents, or to determine the geographical and physical attributes of the commodities, the relevant commodities need to be checked. In this way, we can judge whether the enterprises or individuals who declare are cheating or not. At the same time, the customs inspection also provides reliable data support for the reasonable taxation of the customs.

4.4. Orderly Degree Test of the Supervision System. In the two subsystems of cross-border e-commerce and logistics, the influence degree of each order parameter index on the system is different. In order to improve the accuracy and effectiveness of their collaborative supervision system, different weights should be given to each order parameter index. The weighting method mainly includes the subjective weighting method and the objective weighting method, and the objective weighting method has the principal component analysis method, standard deviation method, entropy weight method critic method, etc. $[28,29]$. The index of order parameters of crossborder e-commerce and logistics in Henan province is calculated by standard deviation formula. In this paper, SPSS18.0 software was used to carry out correlation analysis on the order parameter indexes of the cross-border e-commerce subsystem and logistics subsystem of a city, and the correlation coefficient matrix was obtained. The weights of the order parameter indexes of the cross-border e-commerce subsystem and logistics subsystem of the city were, respectively, calculated. The results are shown in Figure 8. 


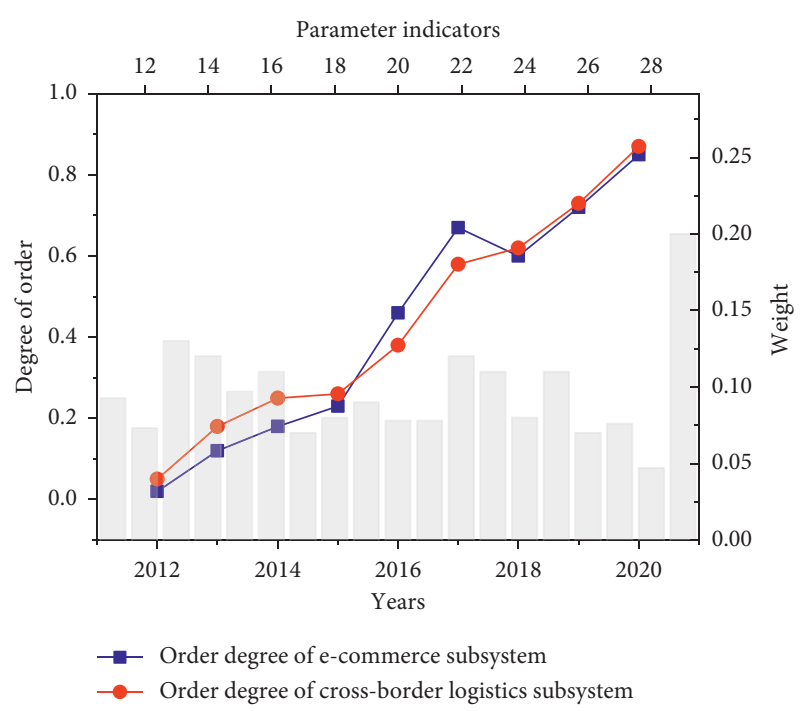

Figure 8: The index weight and order degree of cross-border e-commerce and logistics subsystem.

In addition, the overall synergy degree between crossborder e-commerce and logistics is calculated according to the composite system synergy degree model. The collaborative development trend of cross-border e-commerce and logistics in Henan province plotted by the data results of the order degree of cross-border e-commerce and logistics subsystem and their overall synergy degree is shown in Figure 8.

\section{Conclusion}

This paper proposes a regulatory framework for crossborder e-commerce based on the Internet of Things, aiming at the typical industry of crowd sourced logistics in modern service industry. The system adopts a two-level supervision model: the first level is the supervision of the national authorization center on the logistics service platform and the second level is the supervision of the logistics service platform on the logistics participants. Then, with the business logic of crowd sourcing logistics as a reference, the implementation method of e-commerce logistics transaction regulatory framework is elaborated in detail, and the closedloop security analysis of the scheme is carried out according to the chronological sequence. The analysis results show that the proposed hierarchical and multilayer cross-border e-commerce logistics regulatory framework is safe and controllable. Finally, the corresponding software design architecture is proposed, which realizes the functions of node analysis, optimization of system network structure, implementation and supervision of logistics service based on Internet of Things, and traceability of multimodal transaction objects. In the case of random destruction, the proportion of nodes deleted in the network reaches about $80 \%$, and the network risk efficiency drops to 0 . With the continuous development of e-commerce, cross-border logistics should also keep up with the pace of The Times and constantly improve the logistics and transportation system.
Meanwhile, cross-border logistics involves multiple logistics companies, which can exchange experience, communicate, and coordinate with each other continuously, so that goods can reach customers more quickly, and accelerate the development speed of electronic business and optimization.

\section{Data Availability}

The data used to support the findings of this study are available from the corresponding author upon request.

\section{Conflicts of Interest}

The authors declare that they have no conflicts of interest.

\section{Acknowledgments}

This work was supported by 2020 Scientific Research Projects of Zhejiang Provincial Department of Education (Y202045223).

\section{References}

[1] Z. Liu and Z. Li, "A blockchain-based framework of crossborder e-commerce supply chain," International Journal of Information Management, vol. 52, Article ID 102059, 2020.

[2] J. Lai, "Research on cross-border E-commerce logistics supply under block chain," in Proceedings of the 2019 International Conference Computer Network, Electronic and Automation (ICCNEA), pp. 214-218, Xi'an, China, September 2019.

[3] S. Ma, Y. Chai, and H. Zhang, "Rise of cross-border E-commerce exports in China," China \& World Economy, vol. 26, no. 3, pp. 63-87, 2018.

[4] M. Li, S. P. Guan, and R. R. Du, "Research on the application of customs supervision on cross-border import e-commerce retail business from the perspective of block chain," in Proceedings of the 6th International Conference on Management Science and Management Innovation (MSMI 2019), pp. 74-78, Changsha, China, May 2019.

[5] J. Xie, SWOT Analysis of Cross-Border E-Commerce Development in China under the Background of Internet Plus, pp. 210-213, Atlantis Press, Beijing, China, 2017.

[6] X. Zhang, G. Zhou, J. Cao, and A. Wu, "Evolving strategies of e-commerce and express delivery enterprises with public supervision," Research in Transportation Economics, vol. 80, Article ID 100810, 2020.

[7] D. Sun, L. Fang, and J. Li, "Research on the development of cross-border E-commerce in port cities-A case of Manzhouli city," in Proceedings of the Fourth International Forum on Decision Sciences, pp. 589-596, Beijing, China, February 2017.

[8] P. Porambage, J. Okwuibe, M. Liyanage, M. Ylianttila, and T. Taleb, "Survey on multi-access edge computing for internet of things realization," IEEE Communications Surveys \& Tutorials, vol. 20, no. 4, pp. 2961-2991, 2018.

[9] S. Mohammed, J. Fiaidhi, C. Ramos, T.-H. Kim, W. C. Fang, and T. Abdelzaher, "Blockchain in eCommerce," ACM Transactions on Internet Technology, vol. 21, no. 1, pp. 11-55, 2021.

[10] S. Cao, "A novel optimal selection algorithm for agricultural trade export in block chain-enabled internet of things," Wireless Communications and Mobile Computing, vol. 2021, Article ID 6646398, 2021. 
[11] L. Xiao, F. Guo, F. Yu, and S. Liu, "The effects of online shopping context cues on consumers' purchase intention for cross-border E-commerce sustainability," Sustainability, vol. 11, no. 10, p. 2777, 2019.

[12] J. Mou, G. Ren, C. Qin, and K. Kurcz, "Understanding the topics of export cross-border e-commerce consumers feedback: an LDA approach," Electronic Commerce Research, vol. 19, no. 4, pp. 749-777, 2019.

[13] W. Ai, J. Yang, and L. Wang, "Revelation of cross-border logistics performance for the manufacturing industry development," International Journal of Mobile Communications, vol. 14, no. 6, pp. 593-609, 2016.

[14] M. Zhang, M. Chen, and W. Zuo, "Co-evolution path and its innovative design of China's export cross-border e-commerce: a case study," International Journal of Services Technology and Management, vol. 26, no. 4, pp. 267-290, 2020.

[15] J. Li, "Innovation research of cross border E-commerce shopping guide platform based on big data and artificial intelligence," Frontier Computing, pp. 1785-1792, Springer, Berlin, Germany, 2018.

[16] M. Li, S. Shao, Q. Ye, G. Xu, and G. Q. Huang, "Blockchainenabled logistics finance execution platform for capital-constrained E-commerce retail," Robotics and ComputerIntegrated Manufacturing, vol. 65, Article ID 101962, 2020.

[17] X. Sun, Research on Cross-Border E-Commerce and Financial Services Supervision, pp. 498-502, Atlantis Press, Beijing, China, 2018.

[18] S. Jiangsheng, "The coordinated development of cross border E-commerce and cross border logistics," in Proceedings of the 2018 International Conference on Internet and e-Business, pp. 16-18, Heraklion, Greece, June 2018.

[19] S. Guan, "Smart E-commerce logistics construction model based on big data analytics," Journal of Intelligent \& Fuzzy Systems (Preprint), vol. 1, no. 4, pp. 1-9, 2019.

[20] J. Liu, Research on Strategies of Logistics Talents Training in Higher Vocational Education under the Background of Intelligent Logistics, pp. 932-936, Atlantis Press, Beijing, China, 2018.

[21] J. Zhang and G. Qu, "Physical unclonable function-based key sharing via machine learning for IoT security," IEEE Transactions on Industrial Electronics, vol. 67, no. 8, pp. 7025-7033, 2019.

[22] J. Zhang, C. Shen, H. Su, M. T. Arafin, and G. Qu, "Voltage over-scaling-based lightweight Authentication for IoT security," IEEE Transactions on Computers, 2021.

[23] J. Yang, J. Zhang, and H. Wang, "Urban traffic control in software defined internet of things via a multi-agent deep reinforcement learning approach," IEEE Transactions on Intelligent Transportation Systems, pp. 1-13, 2020.

[24] X. Li and D. Huang, "Research on value integration mode of agricultural E-commerce industry chain based on internet of things and blockchain technology," Wireless Communications and Mobile Computing, vol. 2020, Article ID 8889148, 2020.

[25] W. Wei, Q. Ke, J. Nowak, M. Korytkowski, R. Scherer, and M. Woźniak, "Accurate and fast URL phishing detector: a convolutional neural network approach," Computer Networks, vol. 178, Article ID 107275, 2020.

[26] Y. Li and J. Yang, "Meta-learning baselines and database for few-shot classification in agriculture," Computers and Electronics in Agriculture, vol. 182, Article ID 106055, 2021.

[27] W. Wang, N. Kumar, J. Chen et al., "Realizing the potential of the internet of things for smart tourism with $5 \mathrm{G}$ and AI," IEEE Network, vol. 34, no. 6, pp. 295-301, 2020.
[28] N. Kang, "An overview of "optimal input-output planning model and cross-boundary economic management information system" -combinations between optimal input-output planning model, big data, new cloud computing technologies and internet of things or new internet industry," American Journal of Industrial and Business Management, vol. 09, no. 09, pp. 1800-1830, 2019.

[29] C. S. Yang, "Adoption of software testing in internet of things: a systematic literature mapping," Computing Reviews, vol. 61, no. 2, pp. 72-73, 2020. 